\title{
Design and Development of Zero Electricity Water Pump for Rural Development
}

\author{
Man Djun Lee ${ }^{1, *}$, Jia Yong Chan ${ }^{1}$, Jasper Ling ${ }^{2}$, Pui San Lee ${ }^{1}$ \\ ${ }^{1}$ School of Engineering and Technology, University College of Technology Sarawak, Malaysia \\ ${ }^{2}$ School of Built Environment, University College of Technology Sarawak, Malaysia
}

Received October 23, 2019; Revised November 26, 2019; Accepted November 28, 2019

Copyright $(2019$ by authors, all rights reserved. Authors agree that this article remains permanently open access under the terms of the Creative Commons Attribution License 4.0 International License

\begin{abstract}
This study aims to develop a water pump that utilizes natural hydro energy as driving force to deliver water to a higher ground. The conceptual design of using water wheel to extract kinetic energy from water flow and transfer the energy to power multiple piston pump was created based on the extensive literature review findings. The actual prototype is then built and modified to suit the actual environment considerations. Findings show that single pump is able to produce maximum pressure head of 7.14 meters and the maximum volume flowrate achieved is $19.2 \mathrm{l} / \mathrm{hr}(320 \mathrm{ml} / \mathrm{min})$. However, when multiple piston is connected in series (in this research three pistons is used), the maximum water head increased to 13.77 meters and the maximum volume flowrate about $19.2 \mathrm{l} / \mathrm{hr}$. This result shows that the water pump can be used in remote area or places at higher ground that does not have constant water access. Performance of the whole system can be improved by several factors such as adding more blades to the water wheel, steeper angle and better piston shaft design for water pump, and also proper water sealing of the whole system to prevent head loss and increase the overall performance.
\end{abstract}

Keywords Natural Energy, Piston Pump, Rural Development, Water Pump, Water Supply

\section{Introduction}

Energy is defined as the source of power or the ability of matter to work because of its mass, movement, electric charge, etc. [1]. There are several types of natural energy that had been discovered until today such as electrical, solar, kinetic, potential, nuclear, wind, hydro energy, etc. Law of conservation of energy states that the sum of the energy of a system is always constant, and it is not possible to destroy nor create energy, it can only be relocated or transform into another form of energy [2]. Thus, scientist and professionals had been trying to develop devices that can utilize the natural energy and the principle of conservation of energy such as turbine and pump [4]. Pump is a device that imparts energy to its fluid medium. In the case of water pump, they relocate the energy provided to them to the water. The results are usually the increment of water pressure and change in water velocity. The conversion of energy involved in this case is normally from any form of energy that is provided to the pump, to hydro power [4]. There are many parameters to determine pump performance. Mass flow rate of fluid through the pump is one of the most common factors to determine the pump's performance. However, there is another determinant that governs pump performance that is by its net head $H$ or known as Bernoulli head [4]. Net head has its dimension of length. Even when the pump is operating, the net head is considered as the same column height of water.

General water pump is usually powered by electrical energy. This put those who live in remote area where accessibility to electricity and water is a problem into a hard situation. In Sarawak state alone, the ratio of urban to rural area is $52 \%: 48 \%$ with 1.2 million of populations living in rural settings. Diving in deeper, the rural area is made up of 6,235 villages and that is about 200,000 homes (excluding unexplored region). 1,919 (30\%) of villages have no access to constant electricity and that are 40,000 homes and 250,000 people [5]. Accessibility to the rural villages is one of the main challenges to most of the developing country. The use of renewable energy is attractive for water pumping applications in rural areas of many developing countries [6]. However, considering there is no proper road structure to access to most of the rural villages, importing bulky machinery such as electrical generator and solar panel or other resources such as fuel is often onerous and dangerous [7]. Thus, this study aims to design a water pump that can utilize available hydro energy and without the help of electricity to pump water to the rural villages for their development. In this aspect, the research questions are: 
1. What is the suitable mechanism to pump water by using energy from river in Malaysia?

2. What are the design considerations to develop such water pump?

3. What is the performance of the water pump?

This study is designed to addressed these issues. In most of the present industry, turbomachinery such as pump and turbine are an essential asset. For example, agriculture industry require pump to deliver water and fertilizers to the crops. Housing industry as well require pump to deliver water to higher floor for residents' usage. Thus, by providing a renewable energy water pump to these industries will be able to help in term of reducing the overall operation cost because it uses renewable and clean energy. On the other hand, Malaysia is a country that acquires plenty of natural resources compared to other countries. Malaysia grows its own agricultural products and is internationally dominant in its production line such as rubber and pepper. To maintain these crops in such humongous scale, water delivery system must be at top notch status and it is costly to do so. Thus, by implementing the renewable energy water pump, it helps the agriculture sector to save cost on energy consumption and the extra capital can be focused on ameliorating the economy even further. As mentioned earlier, implementation of renewable energy water pump succors in Malaysia's economy. Improved economy indicates improved lifestyle to the citizen as well. Besides, the renewable energy pump does not require any external energy source, such as electricity. Thus, by using renewable energy will help in reducing the pollution index in Malaysia and provide Malaysian a healthier lifestyle.

\section{Literature Review}

Due to the unique geographical location of Malaysia (Malaysia is located near to the equator), Malaysia has an equatorial climate nature that is hot and humid all year round. However, despite that, Malaysia has a relatively high rainfall per year, measured 98 inches $(248.92 \mathrm{~cm})$ a year compared to other developed country such as United States has only 32.21 inches $(81.81 \mathrm{~cm})$ rainfall per year [8]. Having this amount of rainfall per year indicates that Malaysia has higher cloud coverage and this make Malaysia an unfavorable location for installing solar panel. Other than that, Malaysia's forest type is dominated by a very dense and vast biodiversity tropical rainforest which is known as lowland dipterocarp forest which mainly consist dipterocarp trees from family of Dipterocarpaceae [9]. Dipterocarp trees from Dipterocarpaceae family are mostly large forest emergent species and the maximum height they can grow up to range from $40-70$ meters which allow them to gain the most sunlight compared to other tree species [10]. However, due to this overwhelming height, they can block up to $70 \%$ of sunlight reaching the ground which make the approach of using solar energy to operate the water pump another step further from us [11]. In addition, wind energy could not be used as the power source because wind turbine is absurdly huge and required large space to install it. Installing one wind turbine requires 25 meters diameter empty field and if we were to install multiple wind turbine, the distance between two adjacent turbines has to be five times their turbine diameter (which is 25 meters normally). Not only that, the possible power output by a single normal windmill is only $0.0756 \mathrm{~W}$ per square meter land area which is relatively small compared to the power required by an average water pump which is $150 \mathrm{~W}[12,13]$. Lastly, as mentioned earlier it is also inconvenient and dangerous to bring in bulky equipment into remote area because of transportation difficulty [7]. In short, review from literature suggest that it is more convenient to use hydro energy compared to other form of renewable energy to power up water pump is remote area.

\subsection{Hydro Energy}

Water itself can act as a medium to carry energy such as thermal energy, potential energy and kinetic energy. By utilizing the principle of conservation of energy, several methods were invented to extract energy from water. Hydroelectric is a technology that uses water (hydro) to generate electricity (electric) and dam in one of the common hydroelectric. Dam is a barrier/reservoir that traps water in place, and then releases the water to a turbine system to generate electricity. That is the rough concept of how dam uses water to generate electricity. When the water is trapped, potential energy carried by the water is at its maximum. As the release valve is opened, water is gushed out from the valve and potential energy is converted to kinetic energy. As the water rushes down with its maximum velocity, it will pass through a series of turbine. At that instant, the shaft is turned by the water and kinetic energy is converted to mechanical energy and then to electricity.

Hydraulic Ram is the only pump that does not rely on other form of power but only kinetic energy in the water to pump water. The key mechanism that allows hydraulic ram to pump water without the help of external energy is the water hammer effect. Water Hammer Effect is a phenomenon that utilizes the incompressible characteristic of water to increase the pressure within itself. Imaging the water as a rigid body and travel at a certain velocity, if the water were to be stopped suddenly, the entire system will experience a sudden pressure propagation shock due to the water is incompressible. This might be bad for the system because if the water were to travel in a high velocity and stopped suddenly, it might damage or even blow up the entire system [14]. However, the water hammer effect is not necessarily bad all the time, not in the case of hydraulic ram. Figure below shows the basic components of hydraulic ram. 


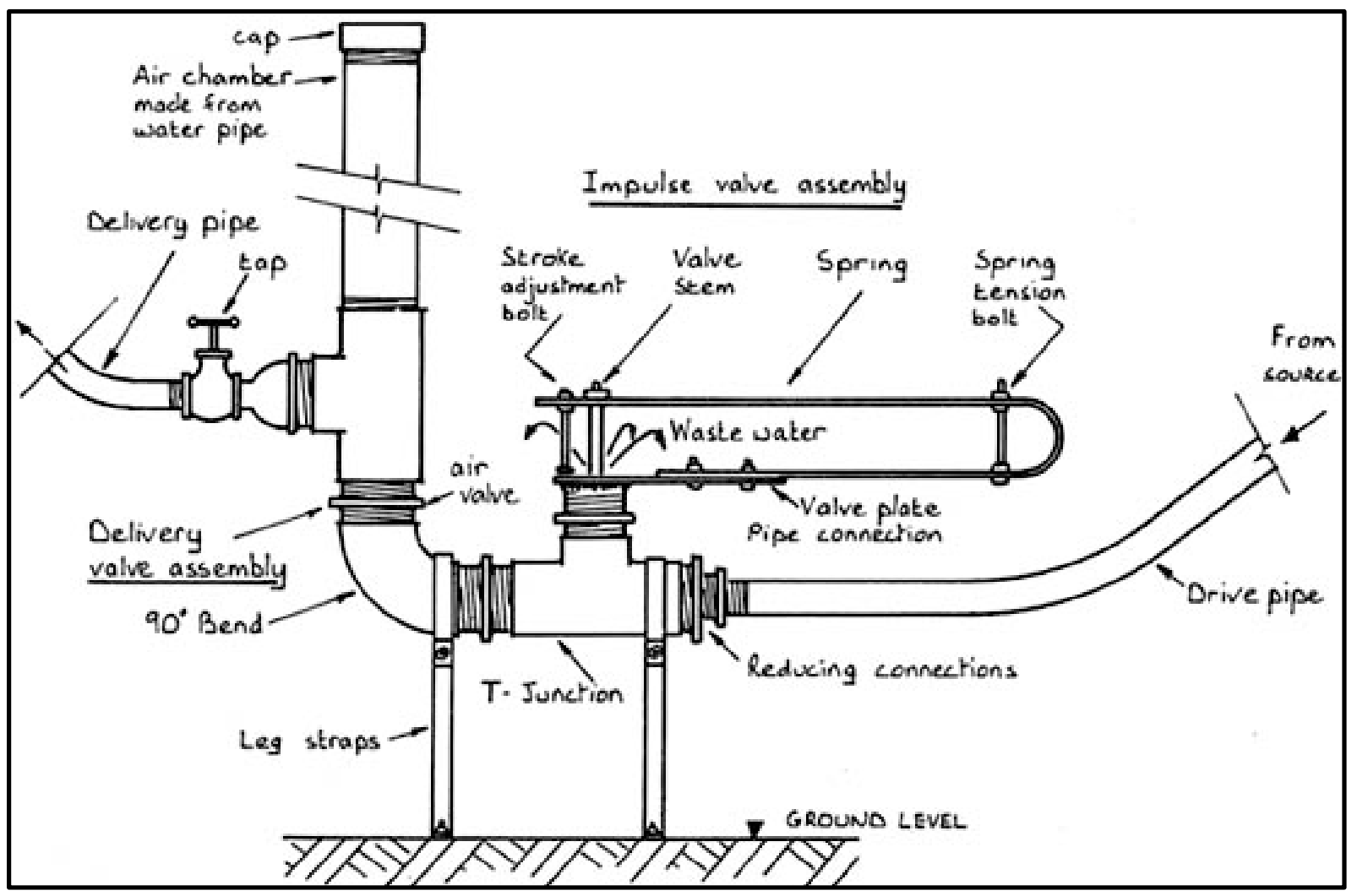

Figure 1. Schematic Diagram of Hydraulic Ram [22]

The whole working process of hydraulic pump will start from water entering the drive pipe from a certain height and flow out from the impulse valve (because the air valve will be closed). As the water had gained enough velocity, it will shut the impulse valve and the water will experience a sudden pressure spike (water hammer effect). As the pressure of the water increases, it will force the air valve to open and water will flow to the air chamber. As the water in air chamber increases, the volume of the air will decrease and its pressure will increase (obeying Boyle's Law, $\left.P_{1} V_{1}=P_{2} V_{2}\right)$. As the air chamber gained enough pressure, it will then push the water into the delivery valve and finally to the designated destination. Thus, the entire process involved no external energy, such as electricity or solar energy. However, the pressure head of such mechanism is not high making it its limitation in water delivery.

Water wheel is one of the oldest methods that use water to generate energy. It was recorded that the first water wheel ever invented was during the first century of $\mathrm{BC}$ [15].The working principle of water wheel is similar to that of dam. It is normally installed on water source. As water passes through its "wheel" that has "fins" on it, the wheel will rotate and convert the kinetic energy to mechanical energy. Figure below illustrates the working principal of a water wheel.

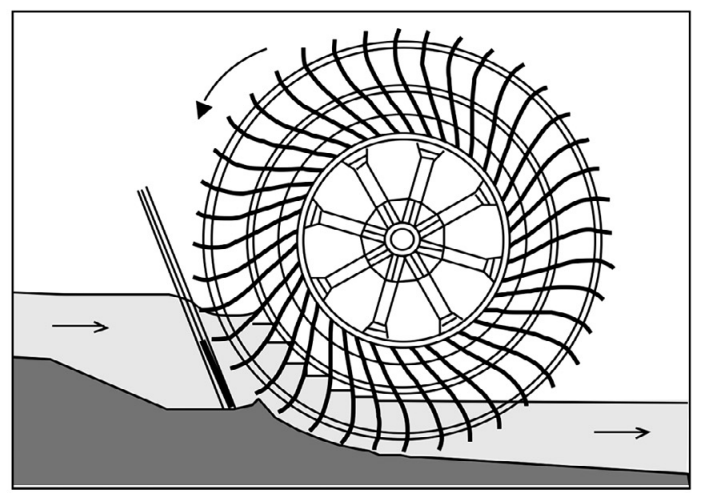

Figure 2. Schematic Diagram of Water Wheel [15]

\subsection{Pumps}

There are two main types of pump which are positive-displacement machines where fluid is transferred into a closed volume and dynamic machines where there is no closed volume. There are many parameters to determine a pump's performance. Mass flow rate of fluid through the pump is one of the most common factors to determine the pump's performance. However, there is another determinant that governs a pump's performance that is by its net head $H$ or known as Bernoulli head [4]. Net head has its dimension of length. Even when the pump is operating, the net head is considered as the same column height of water. Fluid can be put into two extreme situations responding to the net head the fluid possesses during that particular condition. For instance, when a fluid has high net 
head, the mass/volume flow rate of the fluid could be zero $(\dot{V}=0)$. This normally happens when the outlet is block, and the net head in this extreme situation is called the shutoff head. The other extreme situation on the other hand, is when the net head is equal to zero $(H=0)$. At this instant, the mass/volume flow rate will be at its maximum and this flow rate is addressed as free delivery. These two situations are called the extreme situation because this is when the pump does no useful work (extreme situation 1) or there is no load on the pump (extreme situation 2) $[4,16]$. Pump performance graph is acquired when these two situations and pump's reaction under different situation is plotted into a graph. The example of pump performance curve is shown in Figure 3. Thus, pump user has to be aware that a pump can only perform under its own performance curve and should always refer to the pump's performance graph as a guide for the pump to work well under different circumstances $[17,10]$.

\subsection{Gap Analysis}

After extensive review in literature on journal articles, books and internet sources in the field of natural energy water pump and its application domain, several gaps are found such as most research were focusing on integrating photo voltaic technology (solar energy technology) with water pump. However, solar energy is not feasible in Malaysia remote area due to majority of Malaysia's tree are Dipterocarpaceae trees which has extraordinary height that will cover the sunlight and high cloud cover frequency. On the other hand, limited study had been conducted on micro-hydroelectric in the past five years (2014-2018). There are demands in Malaysia because Malaysia has quite a number of remote areas compared to other developed countries [18]. Apart from that, most of the recent research focus on pumps running on electricity or electricity generated by other renewable energies, very little study had focused on developing micro-hydro pump. In this aspect, this study is designed to fill these gaps.

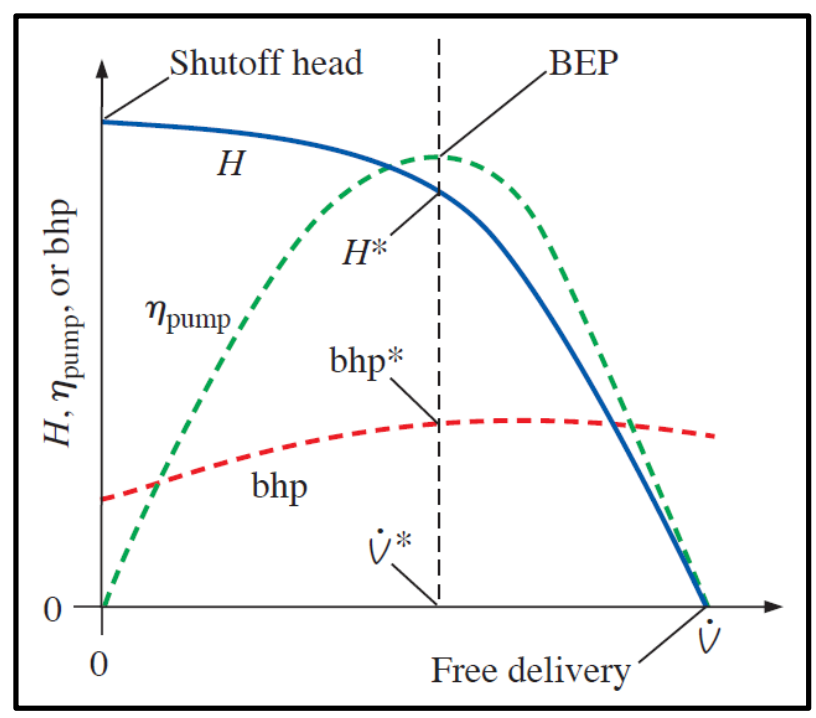

Figure 3. Pump Performance Curve [4]

\section{Methodology}

This study started with literature review on the natural energy water pumping concepts and key parameters governing the performance of the pumps. Upon determining the suitable design considerations and operating parameters, a small-scale model is then developed and tested in laboratory. The performance of the system is recorded and optimized in the later stage. This an applied research. To achieve the objective of this study, the methodology plan is shown in Figure 4. This study is divided into 3 phases which will be explained below: 


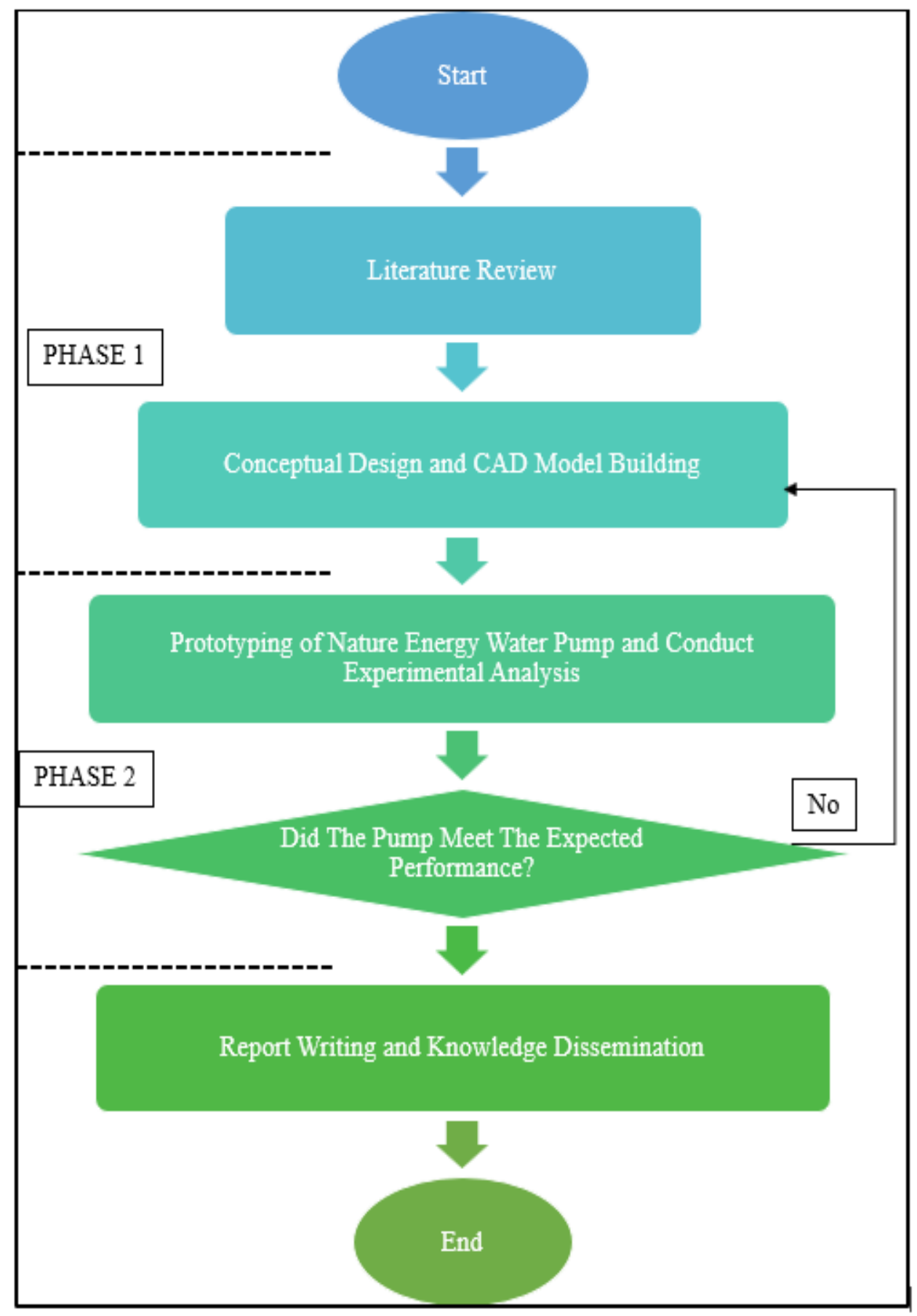

Figure 4. Research Methodology

\subsection{Phase 1: Conceptual Design and CAD Modeling}

In this phase of work, software will be employed to design conceptual model of the device. Initially, the conceptual model would be developed from literature review findings. Published materials related to natural energy water pumps are reviewed and from the findings key parameters for the design are generated. The conceptual design is shown in Figure 5. The concept modelled after water wheels with angle of blade about $45^{\circ}$ with width of blade $1 \mathrm{ft}$ long with diameter of the wheel of $4 \mathrm{ft}$ (Figure 6). The system utilized the flowing river to rotate the wheel too drive a shaft which in turn the shaft will turns 3 piston pumps using cam mechanism to create pressure to deliver water (Figure 7). The piston pumps are connected to check valves to prevent backflow. 


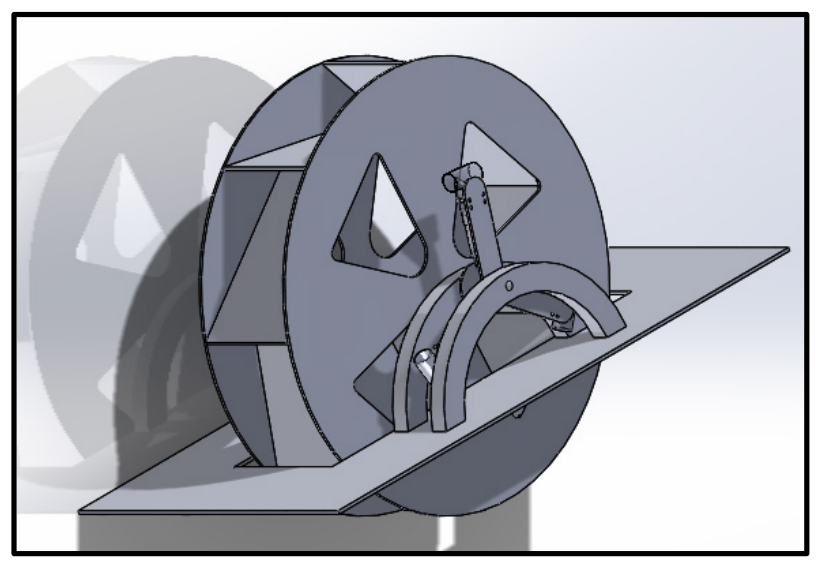

Figure 5. Conceptual Model

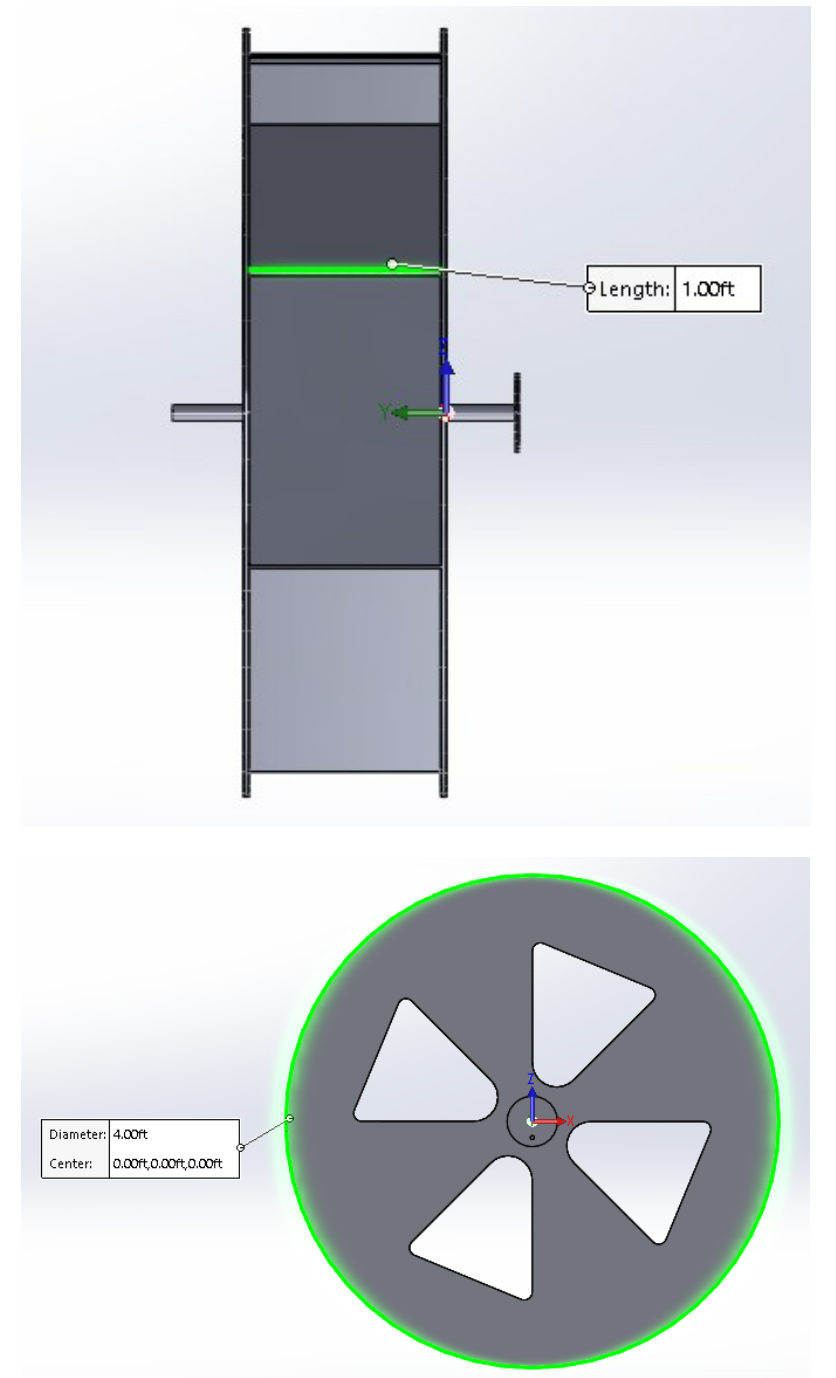

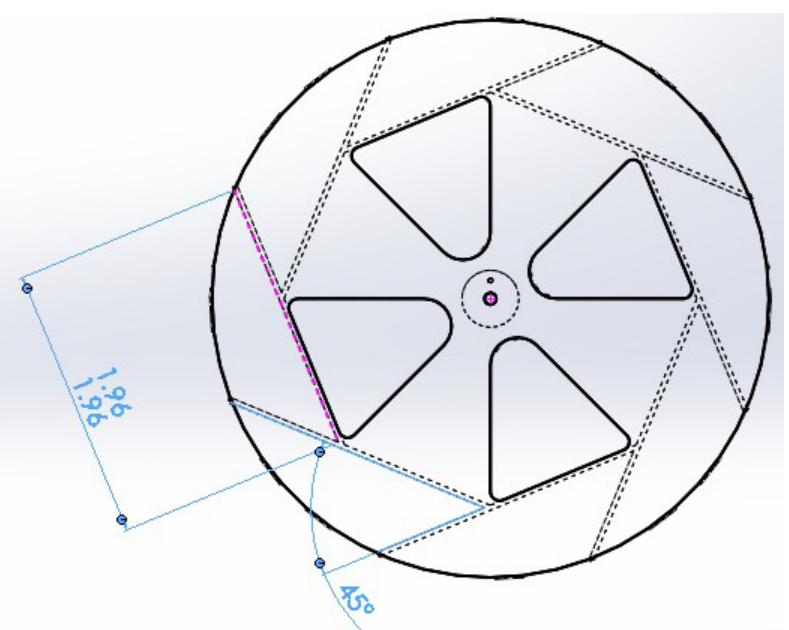

Figure 6. Details of Conceptual Model
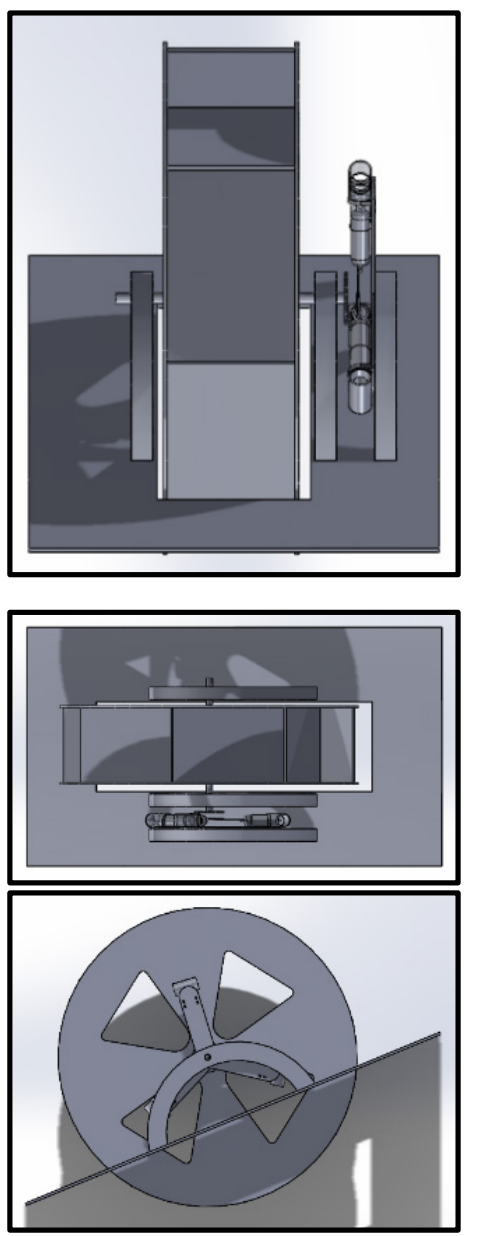

Figure 7. Driving Mechanism for Pump 


\subsection{Phase 2: Rapid Prototyping and Functionality Testing}

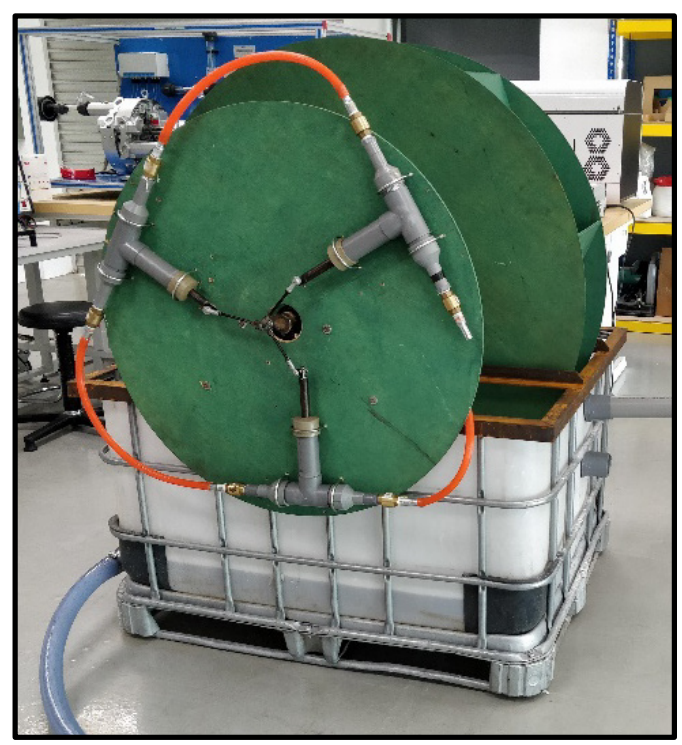

Figure 8. Lab scale prototype

In this phase, a lab scale prototype is developed based on the output from phase 1 . The lab scale prototype developed is shown in Figure 8. Investigation on the prototype is carried out to ensure the functionality of the prototype. The prototype is tested in laboratory by running water through a $1.0 \mathrm{hp}$ pump with average head $25 \mathrm{~m}$ and the flowrate is being controlled and set constant to $50 \mathrm{~L} / \mathrm{min}$ with pipe diameter of $1 \mathrm{inch}$ by ball valve. The prototype is partially submerged in the $1000 \mathrm{~L}$ tank covering about $30 \%$ of the water wheel. This will rougly created flow velocity of 1.65 $\mathrm{m} / \mathrm{s}$ [19]. The purpose of this is to simulate actual river flow conditions in Malaysia with average flow velocity of between 1.5 to $4 \mathrm{~m} / \mathrm{s}$ [12]. The data collected to determine the performance of this prototyte are such as pressure head from guage meter with the working of single or triple pumps and the flowrate that generated from the pumps to plot out pump curve for this system.

\section{Results and Discussiom}

Based on the data collected from laboratory testing, the pump performance curves are generated based on single pump and triple pump configurations. The pump curves are shown in Figure 9.

Results from Fig. 9 show that with driving only single pump, the system is capable of delivering maximum pressure head of $7.14 \mathrm{~m}$ and maximum flow of $320 \mathrm{ml} / \mathrm{min}$. Meanwhile, with similar pumps attached together to form a triple pumps configuration, the system is capable of delivering $13.77 \mathrm{~m}$ of pressure head and $320 \mathrm{ml} / \mathrm{min}$ of water flowrate. The findings indicate that using river flow as a means to pump water is possible. The water wheel mechanism is significant to drive up to three piston pumps with simulated river flow velocity of $1.65 \mathrm{~m} / \mathrm{s}$. The findings indicate that the pressure head generated is quite significant and suitable to deliver water to higher ground. The main cause of low water flowrate is that the size of piston used in this study is relatively small. Increasing the size of piston will significantly improve the flowrate for piston pump. Another limitation for this study is that the water wheel has only eight blades installed. After consecutive studies, it is to realize that the efficiency of water wheel can be increased by increasing the number of the blades, or decrease the angle between two blades [18].

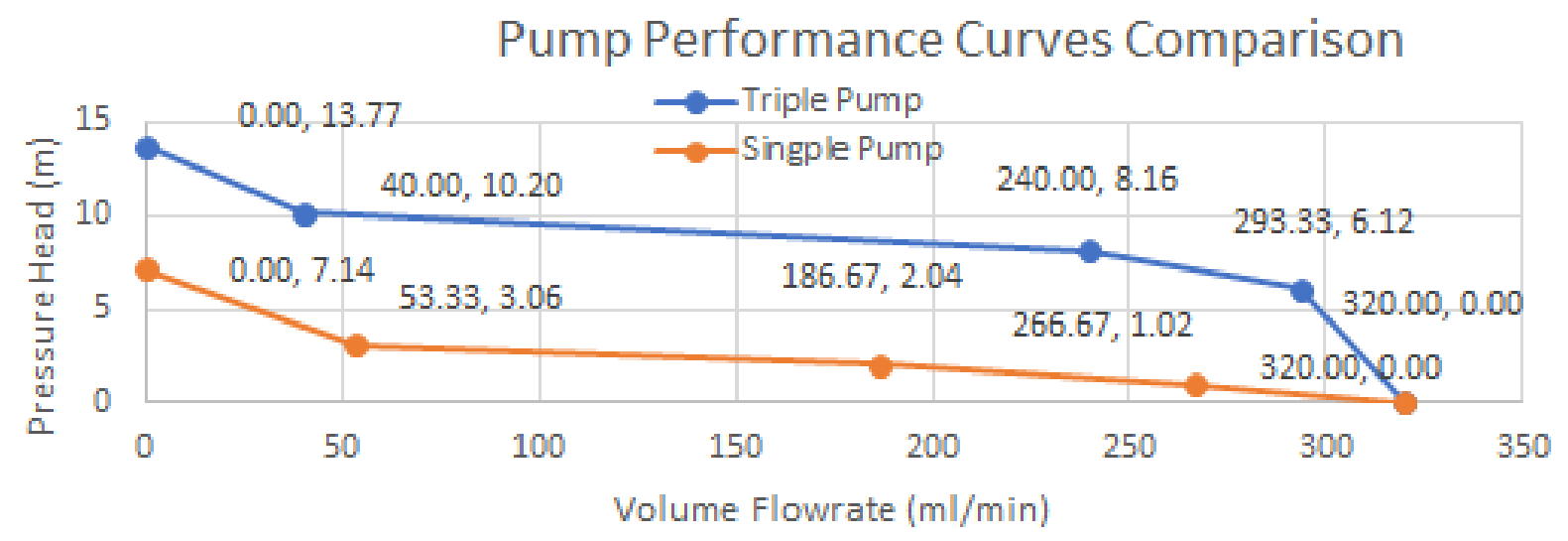

Figure 9. Pump Performance Curves 
The main aim of this study is to design a water pump suitable for the use in remote area that is not connected to national power grid. These areas do not have electricity to power an electrical water pump and also for people, who lives in the higher ground because the outcome of this study indicate that for such application is possible with adequate pressure head. Not only that, the pump is beneficial to the agriculture sector as well. Often, there are limited electric accesses in the planting area due to the challenging geographical conditions and it would be difficult and costly for the owner instills an electric grid system when the area is massive. Thus, the pump can be used to deliver water for agricultural irrigation. In addition, as the water wheel collected the kinetic energy from the water flow, the energy is then converted to rotational energy. Other than delivering water, the rotational energy can be used to run an alternator to produce electricity as well. A simple modification as adding in a gear train could have increase the rotational speed and is decent for generating electrical energy.

\section{Conclusions}

This study is set out to develop a renewable energy water pump to assist rural development without assess to national power grid. A lab scale prototype was developed to test the concept generated from literature review findings. The primary energy required to drive the pump is flowing energy from the river to drive the water wheel. Upon collecting the kinetic energy from the river, it is converted to rotational energy and mechanical energy to power the pump and thus no external source of unrenewable energy is involved. The core concept throughout the experiment is to impart and extract energy from water to execute other significant task where in this study is to deliver water to secondary location usually at an elevated height. The findings suggested that it is possible to use river flow as a mean to pump water and the pressure head is significant. The design could be improved further to increase the overall performance such as increase size of piston, increase the number of blades and modify the blade angles.

\section{Acknowledgements}

Authors would like to express gratitude for the financial support received from University College of Technology Sarawak (UCTS) under internal research grant scheme (UCTS/Research/4/2018/8).

\section{REFERENCES}

[1] Hornby, A. S. 2015. Oxford Advanced Learner's Dictionary, hlm. 6th Edisi. Oxford University Press.

[2] Mohamed, N. S. \& Sulaiman, Z. A. 2012. Physics College. Malaysia: IPTA Publication Sdn. Bhd.

[3] Nehrenheim, E. 2018. Energy and Natural Resources. Dlm. Dellasala (pnyt.) \& Goldstein (pnyt.)., hlm. 441-442. Oxford: Elsevier. doi: https://doi.org/10.1016/B978-0-12-8 09665-9.05353-2

[4] Cengel, Y. A. \& Cimbala, J. M. 2014. Fluid Mechanics, Fundamentals and Applications, Third Edition in SI Units., hlm. 3rd Edisi. Mc Graw Hill Education.

[5] Shiun, C. 2016. Rural Electrification in Sarawak, Malaysia: Challenges for Mini-Hydro \& Solar Hybrid Solutions. Sarawak.

[6] Mohamed, E. S., Papadakis, G., Mathioulakis, E. \& Belessiotis, V. 2005. The effect of hydraulic energy recovery in a small sea water reverse osmosis desalination system; experimental and economical evaluation. Desalination 184(1-3): 241-246. doi:10.1016/j.desal.2005. 02.066

[7] Argaw, N. 2004. Renewable Energy Water Pumping Systems Handbook. Denver, Colorado.

[8] National Oceanic and Atmospheric Administration (NOAA), U. D. of C. 2017. National Climate Report - Annual 2017. NOAA.

[9] World Wide Fund for Nature (WWF) - Malaysia. 2018. The Malaysian Rainforest. WWF.

[10] World Wide Fund for Nature (WWF). 2018. Low Land Forest. WWF.

[11] Engkik, S., Saw, L. G. \& Richard Chung, C. K. 2004. Tree Flora of Sabah and Sarawak. Malaysia: Sabah Forestry Department, Forest Research Institute Malaysia (FRIM), Sarawak Forestry Department.

[12] Saupi, A. F. M., Mailah, N. F., Radzi, M. A. M., Mohamad, K. B., Ahmad, S. Z. \& Soh, A. C. 2018. An illustrated guide to estimation ofwater velocity in unregulated river for hydrokinetic performance analysis studies in East Malaysia. Water (Switzerland) 10(10). doi:10.3390/w10101330

[13] Saw, S. H. 2007. The Population of Peninsular Malaysia, hlm. 1st Edisi. Malaysia: Institute of Comptes Rendus Mécanique 345(8): 570-580. Southest Asian Studies Singapore.

[14] Thorley, A. R. D. 2004. Fluid Transients in Pipeline Systems: A Guide to the Control and Suppression of Fluid Transients in Liquids in Closed Conduits, hlm. 2nd Edisi. Professional Engineering Publishing.

[15] Viollet, P.-L. 2017. From the water wheel to turbines and hydroelectricity. Technological evolution and revolutions. doi: https://doi.org/10.1016/j.crme.2017.05.016

[16] Ismail, M. A., Othman, A. K., Islam, S. \& Zen, H. 2014. End Suction Centrifugal Pump Operating in Turbine Mode for Microhydro Applications 2014.

[17] Christopher Teh, B. S. 2010. Possibility of electricity from wind energy in Malaysia: Some rough calculations.

[18] Behrouzi, F., Nakisa, M., Maimun, A. \& Ahmed, Y. M. 2016. 
Renewable energy potential in Malaysia: Hydrokinetic river/marine technology. Renewable and Sustainable Energy Reviews 62: 1270-1281. doi:10.1016/j.rser.2016.0 5.020

[19] Shahidul, M. I., Tarmizi, S., Yassin, A., Othman, A. K., Zen, H., Hung, T. C. \& Lee, M. D. 2015. Modeling the Energy Extraction from In-stream Water by Multi Stage Blade System of Cross Flow Micro Hydro Turbine. Procedia Engineering 105(Icte 2014): 488-494. doi:10.1016/j.proen g.2015.05.081 